\title{
Endocrine gland-derived vascular endothelial growth factor in rat pancreas: genetic expression and testosterone regulation
}

\author{
Angélica Morales, Sumiko Morimoto, Lorenza Díaz, Guillermo Robles ${ }^{1}$ and Vicente Díaz-Sánchez ${ }^{2}$ \\ Departamento de Biología de la Reproducción, Instituto Nacional de Ciencias Médicas y Nutrición Salvador Zubirán. Vasco de Quiroga \# 15 Tlalpan, \\ 14000 México DF, Mexico \\ ${ }^{1}$ Departamento de Medicina Experimental, Facultad de Medicina, Universidad Nacional Autónoma de México 04510, México DF, Mexico \\ ${ }^{2}$ MEXFAM A.C. Juárez 208 Tlalpan, 14000 México DF, Mexico \\ (Correspondence should be addressed to A Morales; Email: amorales@quetzal.innsz.mx)
}

\begin{abstract}
Endocrine gland-derived vascular endothelial growth factor (EG-VEGF) is an endothelial cell mitogen, expressed essentially in steroidogenic cells. Recently, the expression of EG-VEGF in normal human pancreas and pancreatic adenocarcinoma has been demonstrated. Epidemiologically, pancreatic carcinogenesis is more frequent in males than females, and given that androgen receptors and testosterone biotransformation have been described in pancreas, we hypothesized that testosterone could participate in the regulation of EG-VEGF expression. In this study, we investigated the regulation of EG-VEGF gene expression by testosterone in normal rat pancreatic tissue and rat insulinoma cells (RINm5F). Total RNA was extracted from rat pancreas and cultured cells. Gene expression was studied by realtime PCR and protein detection by immunohistochemistry.
\end{abstract}

Serum testosterone was quantified by RIA. Results showed that EG-VEGF is expressed predominantly in pancreatic islets and vascular endothelium, as well as in RINm5F cells. EG-VEGF gene expression was lower in the pancreas of rats with higher testosterone serum levels. A similar effect that was reverted by flutamide was observed in testosterone-treated RINm5F cells. In summary, testosterone down-regulated EG-VEGF gene expression in rat pancreatic tissue and RINm5F cells. This effect could be mediated by the androgen receptor. To our knowledge, this is the first time that a direct effect of testosterone on EG-VEGF gene expression in rat pancreas and RINm5F cells is demonstrated.

Journal of Endocrinology (2008) 197, 309-314

\section{Introduction}

The endocrine gland-derived vascular endothelial growth factor (EG-VEGF) belongs to the AVIT protein family. The first described member of this family was originally isolated from snake venom and frog skin secretions. The aminoterminal sequence of these proteins is identical; the first four residues are conserved in all of them, giving the name to this family (Soga et al. 2002, Kaser et al. 2003, Ferrara et al. 2004). EG-VEGF regulates diverse biological functions associated with neuronal survival, angiogenesis, cell proliferation, migration, and fenestration (formation of membrane discontinuities) in capillary endothelial cells (LeCouter et al. 2004, Dorsch et al. 2005, Ngan et al. 2007a). The human EG-VEGF gene promoter has a binding site for steroidogenic factor 1, which is essential in controlling the expression of all the steroidogenic enzymes and cholesterol transporters required for steroidogenesis (Bakker et al. 2001, Morales et al. 2006). EG-VEGF regulation is poorly understood; nevertheless, recent studies have shown that hypoxia induces EG-VEGF expression, suggesting a role of this factor in tumorigenesis. In addition, EG-VEGF has been associated with certain EG cancers such as prostate carcinogenesis (Pasquali et al. 2006), and we have recently demonstrated the expression of EG-VEGF in normal human pancreas and pancreatic adenocarcinoma (Morales et al. 2007a). Epidemiologically, pancreatic carcinogenesis is more frequent in males than females. Current data suggest that male-to-female ratio is 3:1 that varies with age and ethnicity (Hidalgo et al. 2004). In particular, adenocarcinoma of the pancreas is the most frequent tumor of this organ, and its incidence in males is also more frequent than females with a proportion of 1.75:1 (Morales et al. 2007b). Considering the later, the presence of androgen receptors (Díaz-Sánchez et al. 1995), and androgen biotransformation in the pancreas (Fernandéz-del Castillo et al. 1991), we hypothesized that testosterone could participate in the regulation of EG-VEGF expression. This work was undertaken to 1) study the expression and regulation of EG-VEGF in the rat pancreas under different endocrine conditions, 2) analyze the localization of EG-VEGF in rat pancreatic tissue, and 3) study the regulation of EG-VEGF by testosterone in RINm5F cells. 


\section{Materials and Methods}

\section{Animal procedures}

Animal procedures were carried out in accordance with the Official Mexican Guideline for the Care and Use of Laboratory Animals (NOM-062-ZOO-1999) and approved by the Institutional Research Committee. Animals were housed under controlled conditions of temperature $\left(24-26^{\circ} \mathrm{C}\right)$, humidity $(30-50 \%)$ and $12 \mathrm{~h}$ light: $12 \mathrm{~h}$ darkness cycles, with access to water and standard rodent chow made available ad libitum until killing.

\section{Experimental groups}

Fifty adult male Wistar rats (Rattus norvegicus; 200-250 g) were divided into five groups of five rats each, in two independent experiments: 1) intact; 2) castrated; 3-5) castrated and substituted with testosterone enanthate (TE; Shering Mexicana, Mexico City, Mexico) and killed 3, 5, or 7 days post-treatment respectively. Gonadectomy was performed under ketamine-xylazine anesthesia, a single cutaneous incision was made through the scrotal sac and the peritoneal cavity was entered to expose the testes. The testicular bundles were double ligated with 4-0 silk suture and the testes removed. The cutaneous incision was closed with 5-0 silk suture.

\section{Treatments}

Three days after gonadectomy, the animals from group 2 received an i.m. injection of $500 \mu \mathrm{l}$ vehicle (corn oil), whereas animals of groups 3, 4, and 5 were injected with TE (20 $\mathrm{mg} / \mathrm{kg}$ body weight) in a single dose. Rats from groups 2 and 3 were killed 3 days after the injection, whereas rats from groups 4 and 5 after 5 and 7 days respectively.

\section{Testosterone quantification}

The levels of testosterone were determined in rat serum samples by specific RIA using commercial kits (Diagnostic Product Corporation, Los Angeles, CA, USA). The sensitivity limit of the RIA was $2.47 \mathrm{pg} / \mathrm{ml}$, the intra- and interassay coefficients of variation were 4.9 and $8 \cdot 2 \%$ respectively.

\section{$R N A$ isolation and $q P C R$ analysis}

In order to achieve optimal relative expression results, for the in vivo studies all comparisons were made starting with same mass of tissue, which corresponded to pancreatic tail. Total RNA was extracted from pancreas immediately after resection by homogenizing in Trizol reagent (Invitrogen). For the in vitro studies, plates containing insulinoma cells were scrapped using a sterile rubber policeman with $1 \mathrm{ml}$ Trizol reagent. In all cases, the amount and quality of RNA were estimated spectrophotometrically at $260 / 280 \mathrm{~nm}$ and a constant amount of RNA (1 $\mu \mathrm{g})$ was reverse transcribed using the transcriptor RT system (Roche Applied Science). Primers and probes were designed by Roche Universal ProbeLibrary Assay Design Center (https://qpcr2.probefinder.com/organism.jsp). The primer pairs were targeted to the genes coding for rat EG-VEGF and $\beta$-actin. Sequences used were as follows: EG-VEGF, GGCTGTGTACCCCTCTGG and CGTTTCCTAAAGAAAGGGATCTT and $\beta$-actin, TGCCCTAGACTTCGAGCAAG and GGCAGCTCATAGGCTCTTETCC. The sizes of the resulting amplicons were 76 and 72 nucleotides, and the probes utilized were 12 and 69 from the Universal Probe Library (Roche) for EG-VEGF and $\beta$-actin respectively. Afterward, identical qPCR conditions were performed and normalization was achieved in all cases by comparing our gene of interest against the housekeeping gene $\beta$-actin. Real-time PCRs were carried out using the LightCycler 2.0 (Roche), according to the following protocol: activation of Taq DNA polymerase and DNA denaturation at $95^{\circ} \mathrm{C}$ for $10 \mathrm{~min}$, proceeded by 45 amplification cycles consisting of $10 \mathrm{~s}$ at $95^{\circ} \mathrm{C}, 30 \mathrm{~s}$ at $60^{\circ} \mathrm{C}$, and $1 \mathrm{~s}$ at $72^{\circ} \mathrm{C}$. In order to facilitate comparisons among different experiments, all samples were compared with the intra-experiment calibrator. The calibrator was used for normalization of the final results, and for each experiment performed the calibrator was either the control group of rats (intact animals) or the vehicle-treated cells, and these values were arbitrarily given a value of 1 . PCR efficiency was determined by a standard curve for each set of primers. After confirmation of linearity, both PCR efficiencies were near 2 .

\section{Insulinoma cell line}

The immortalized rat insulinoma cell line (RINm5F) was a generous gift from Dr Marcia Hiriat (Instituto de Fisiología Celular UNAM, Mexico). Cells were maintained in culture with RPMI 1640 medium, supplemented with $2 \mathrm{~g} / \mathrm{l}$ sodium bicarbonate, $2.4 \mathrm{~g} / 1$ HEPES, $10 \%$ fetal bovine serum, $100 \mathrm{U} / \mathrm{ml}$ penicillin, $100 \mathrm{mg} / \mathrm{ml}$ streptomycin and $0.25 \mathrm{mg} / \mathrm{ml}$ fungizone (all from Invitrogen) at $37^{\circ} \mathrm{C}$ in humidified 5\% $\mathrm{CO}_{2}-95 \%$ atmospheric air. Experiments were performed in serum-free medium, and in all cases the cells were grown to $75 \%$ confluence. The cells were incubated in the presence of different testosterone concentrations $\left(1 \times 10^{-11}-1 \times 10^{-8} \mathrm{M}\right)$ for $24 \mathrm{~h}$. The flutamide dose used in our studies was $1 \times 10^{-7} \mathrm{M}$. After culture, the cells were processed with $1 \mathrm{ml}$ Trizol reagent for RNA extraction, as described previously.

\section{Immunohistochemistry procedure}

A fragment of each pancreatic tissue was fixed in 10\% neutral buffered formalin and embedded in paraffin according to conventional procedures. Tissue sections $(7 \mu \mathrm{m}$ thick) placed on poly-L-lysine-coated slides were deparaffinized in xylene and rehydrated in graded ethanol solutions. The sections were 
blocked in 10\% normal serum diluted in PBS with $1 \%(\mathrm{w} / \mathrm{v})$ BSA (Sigma Chemical) for $60 \mathrm{~min}$. After washing with PBS, each section was incubated with goat polyclonal IgGEG-VEGF antibody (1:300, cat. sc-30343; Santa Cruz Biotechnology Inc., Santa Cruz, CA, USA) overnight at $4{ }^{\circ} \mathrm{C}$. Afterward the sections were incubated with a second rhodamine-conjugated chicken anti-goat IgG antibody (1:100, cat. sc-2860; Santa Cruz Biotechnology Inc.) for $60 \mathrm{~min}$ at room temperature. Finally, the sections were washed and coverslipped with non-fade aqueous mounting medium (Shandon, Pittsburgh, PA, USA). Digitalized images of the same microscopic field were captured with specific filters for rhodamine. Double immunohistochemistry staining was performed in RINm5F. Cells were permeabilized and subsequently incubated overnight with goat polyclonal IgGEG-VEGF antibody (1:300, cat. sc-30343; Santa Cruz Biotechnology Inc). Subsequently, a rhodamine-conjugated chicken anti-goat IgG was used as the secondary antibody $(1: 100)$. After this procedure, the rabbit polyclonal IgGinsulin antibody was added (1:300, cat. sc-9168; Santa Cruz Biotechnology Inc.) and incubated overnight at $4{ }^{\circ} \mathrm{C}$. Finally, fluorescein isothiocyanate (FITC)-conjugated mouse antirabbit IgG (cat. sc-2353; Santa Cruz Biotechnology Inc.) was used as the secondary antibody $(1: 100)$, and the slides were observed with a confocal microscope (TCS-SP5; Leica, Wetzlar, Germany) with oil immersion $40 \times$ objective. FITC was excited with $488 \mathrm{~nm}$ wavelength, and the emitted light was bandpassed through the photomultiplier tube (PMT) (FITC, 500-535 nm), while rhodamine was excited with $543 \mathrm{~nm}$ wavelength, and the emitted light was bandpassed through the PMT (rhodamine, 550-700 nm). Confocal images were viewed and processed by Leica Microsystems. Examination of negative controls was performed to confirm the absence of nonspecific immunofluorescent staining, crossimmunostaining, or fluorescence bleed-through. Negative control was performed in pancreatic tissue without the addition of primary antiserum or the secondary antibody.

\section{Statistical analyses}

All data were expressed as the mean \pm s.D. Differences between groups were found using ANOVA. The differences were considered significant when $P<0 \cdot 05$.

\section{Results}

\section{Testosterone serum levels}

In order to assess hormonal status, testosterone was measured in the serum of experimental animals. As expected, testosterone was almost undetectable in castrated rats (group 2 ), while it was significantly higher in substituted animals (groups 3-5) compared with controls (Fig. 1A).
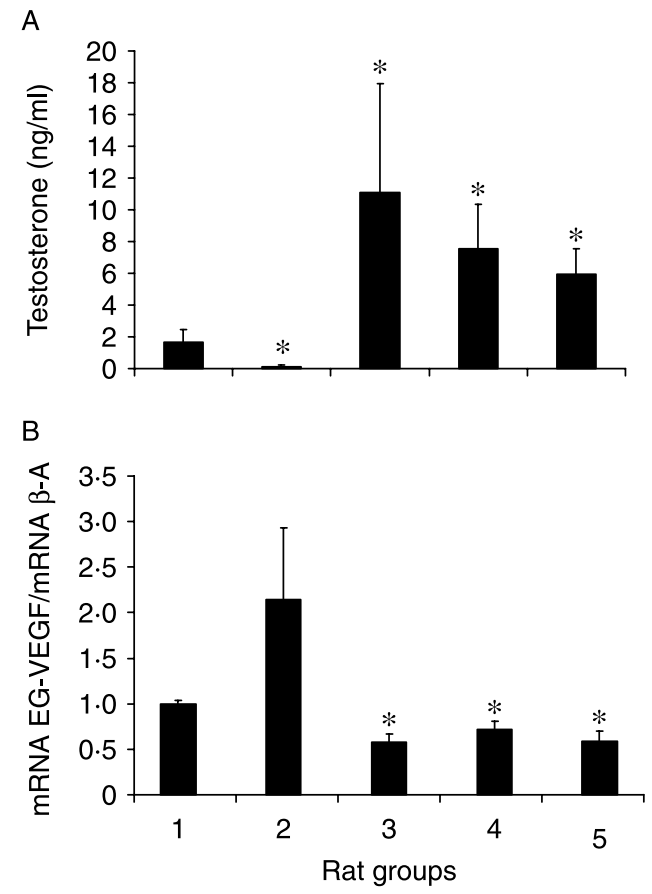

Figure 1 Testosterone concentrations and EG-VEGF mRNA in intact and treated rats. (A) Testosterone serum levels in 1) intact; 2) gonadectomized; 3-5) gonadectomized and testosterone-substituted rats, killed 3, 5, and 7 days post-treatment respectively. (B) Regulation of EG-VEGF gene expression by testosterone in rat pancreas. The levels of EG-VEGF mRNA decreased significantly in castrated and substituted males when compared with groups 1 and 2 . Results were normalized against $\beta$-actin $(\beta-A)$ mRNA. Vehicle data were arbitrarily given a value of 1 . Data are shown as the mean \pm s.D. ${ }^{*} P<0.05$ compared with group $1, n=10$.

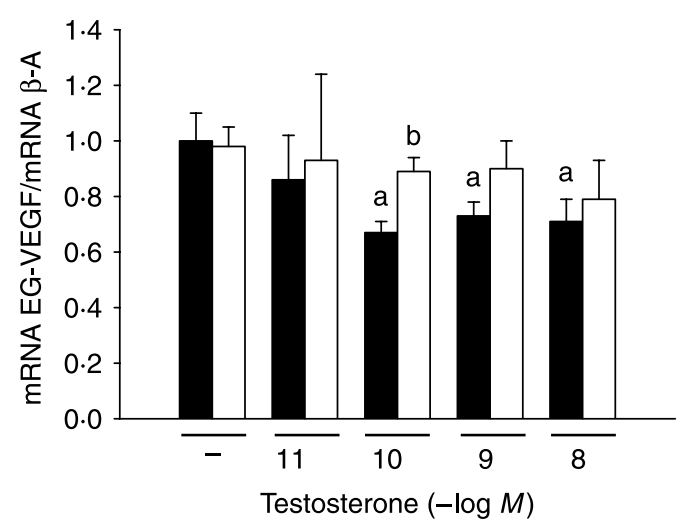

Figure 2 Regulation of EG-VEGF gene expression in RINm5F. Cells were treated for $24 \mathrm{~h}$ with different testosterone concentrations (filled bars). Simultaneous incubations of testosterone in the presence of flutamide are shown as open bars. ${ }^{a} P<0.05$ compared with vehicle, ${ }^{b} P<0.05$ compared with the same testosterone dose without flutamide. Results were normalized against $\beta$-actin $(\beta-A)$ mRNA. Vehicle data were arbitrarily given a value of 1 . Data are shown as the mean \pm s.D. of at least four different experiments. 


\section{EG-VEGF gene expression}

In order to study the possible effect of testosterone on EG-VEGF gene expression, quantitative PCR was performed in both the in vivo and in vitro models. In pancreatic tissue, testosterone substitution provoked a significant reduction in the EG-VEGF gene expression compared with intact animals (Fig. 1B). In the in vitro model, testosterone treatment $(1 \times$ $\left.10^{-10}-1 \times 10^{-8} \mathrm{M}\right)$ significantly reduced EG-VEGF mRNA, in a similar manner to the in vivo model. Flutamide addition to the culture media reverted this effect, increasing EG-VEGF mRNA to control levels (Fig. 2).
Immunodetection of EG-VEGF

In all rat groups, positive staining for EG-VEGF was localized. The label was preferentially visualized in pancreatic islets and endothelial cells of blood vessels (Fig. 3A and B respectively). An ovarian section was used as positive control, and primary follicles showed higher staining in the granulosacells (Fig. 3C), as described previously (Fraser et al. 2005, Kisliouk et al. 2005). No immunolabeling was found in negative controls (Fig. 3D). Double immunohistochemistry staining in cultured RINm5F cells was performed in order to assess coexpression of EG-VEGF and insulin. Results demonstrated
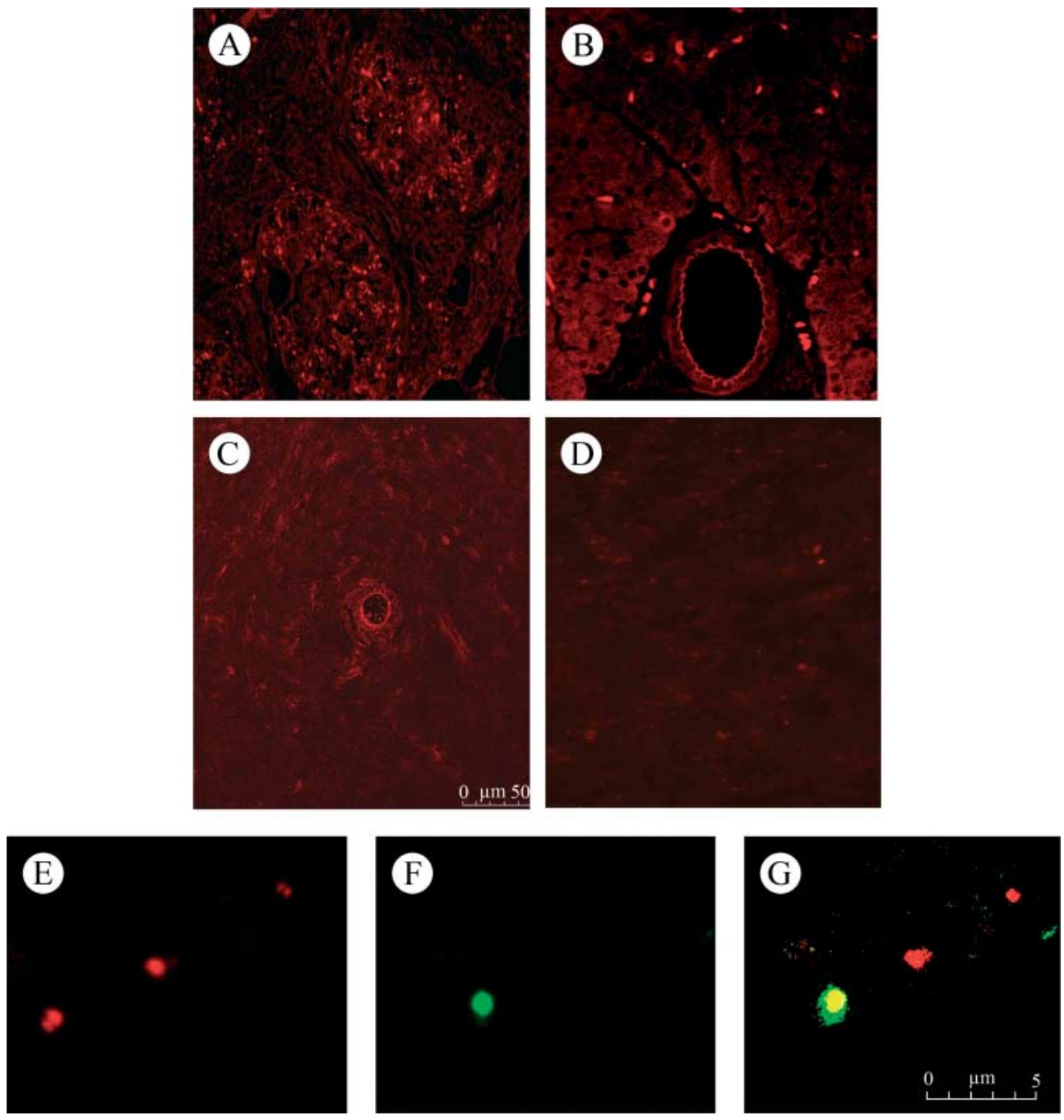

Figure 3 Representative immunohistochemical staining for EG-VEGF. EG-VEGF positive label was localized in (A) cells of pancreatic islet and (B) the endothelium of pancreatic blood vessels. (C) Ovary was used as positive control. (D) Pancreatic tissue without the addition of primary antibody was used as negative control. Confocal microscopy of double-labeled immunofluorescence of RINm5F cells for (E) EG-VEGF (red) and (F) insulin (green). (G) The superposition of $E$ and $F$; co-localization of both EG-VEGF and insulin is shown in yellow. Scale bar in $\mu \mathrm{m}$. 
that not every cell expressed EG-VEGF and insulin; only sporadic immunoreactivity was found. EG-VEGF is shown in Fig. 3E and $\mathrm{G}$ with rhodamine label (red), insulin is shown as green staining in Fig. 3F and G, and co-localization of both insulin and EG-VEGF in yellow in Fig. 3G.

\section{Discussion}

The results presented in this article demonstrated for the first time the presence of EG-VEGF in the rat pancreas and the rat insulinoma cell line RINm5F, and showed the regulation of EG-VEGF gene expression by testosterone in two different models: in vivo and in vitro. The relationship between steroid hormones and pancreatic function has been poorly discussed and not very well understood. In general, there is a lack of recognition among the scientific community about the importance of steroids in pancreatic functions (Morales et al. 1999, 2007b, Robles-Diaz \& Duarte Rojo 2001). However, steroid hormones have been implicated in endocrine processes in the pancreas; specifically, testosterone stimulates insulin release from pancreatic islets (Morimoto et al. 2001). Regarding EG-VEGF, LeCouter et al. (2001) cloned EG-VEGF gene and described that it is expressed only in hormone-producing cells such as those in the ovaries, testis, and placenta; however, they did not detect this factor in human pancreas, probably because northern blot analysis was used. Recently, our group demonstrated the expression of EG-VEGF in normal human pancreas and pancreatic adenocarcinoma using semi-quantitative RT-PCR (Morales et al. 2007a). In this study, using real-time qPCR and immunohistochemestry, we demonstrated the presence of EG-VEGF transcripts and EG-VEGF protein in islets cells and vascular endothelia of rat pancreatic tissue, as well as in insulinoma cells. Normal endocrine tissues and different tumors are characteristically highly vascularized and possess a dense and specialized permeable microvascular endothelium. Pancreatic islets have a highly fenestrated capillary network, which is important to provide nutrients and disperse hormones to the systemic circulation. This vascularization is attributable to potent local angiogenic agents like EG-VEGF. Interestingly, EG-VEGF is up-regulated by hypoxia, a factor known to regulate the expression of different genes that promote tumor growth and are involved in tissue invasion, cell proliferation and angiogenesis (LeCouter \& Ferrara 2002, Zhang et al. 2003, Koyama et al. 2006). Considering that EG-VEGF has been associated with cancer progression (Goi et al. 2004), and that pancreatic cancer is more frequent in males than females (Ganepola et al. 1999, Lygidakis et al. 2005), we studied EG-VEGF regulation by testosterone. The rationale for this assumption was based on the clinical reports of a significant increase in the survival rate of patients with pancreatic cancer, who were treated with the antiandrogen flutamide (Negi et al. 2006, Konduri et al. 2007). Nevertheless, contrary to our expectations, the findings in this study showed that testosterone reduced EG-VEGF mRNA in both models used. This effect appeared to be mediated by the androgen receptor. Because antiandrogens are used in the treatment for pancreatic carcinoma with relatively good results, and considering the data presented herein, we suggest that the possible therapeutic effects of flutamide might not target EG-VEGF. Other possibility is that EG-VEGF may play a marginal role in promoting angiogenesis in this type of cancer, which should be taken into account when considering EG-VEGF-targeted antiangiogenic therapy. The lack of association between cancer and EG-VEGF has also been described in different types of malignant pathologies (Pasquali et al. 2006, Ngan et al. 2007b). Nevertheless, a proangiogenic role of EG-VEGF in pancreatic cancer must not be completely excluded, since this factor is up-regulated by hypoxia (Koong et al. 2000, Büchler et al. 2004, Couvelard et al. 2005), a process strongly involved in tumorigenesis; thus, further studies are needed in order to get insights into the association between the EG-VEGF and the different kinds of pancreatic cancers, as well as the participation of this factor in angiogenesis in normal pancreas.

\section{Acknowledgements}

We are grateful to Veronica Rodriguez for technical assistance and Dr Mara Berenice Torres for microscopic evaluation, and also to Departamento de Biología Celular y Tisular and Departamento de Embriología, Facultad de Medicina, UNAM for equipment facilities. This work was partially supported by a grant (521550) from CONACYT, México. The authors declare that there is no conflict of interest that would prejudicethe impartiality of this scientific work.

\section{References}

Bakker M, Zhao L \& Parker KL 2001 Approaches to define the role of SF-1 at different levels of the hypothalamic-pituitary steroidogenic organ axis. Molecular and Cellular Endocrinology 179 33-37.

Büchler P, Reber HA, Lavey RS, Tomlinson J, Büchler MW, Friess H \& Hines OJ 2004 Tumor hypoxia correlates with metastatic tumor growth of pancreatic cancer in an orthotopic murine model. Journal of Surgical Research 120 295-303.

Couvelard A, O'Toole D, Leek R, Turley H, Sauvanet A, Degott C, Ruszniewski P, Belghiti J, Harris AL, Gatter K et al. 2005 Expression of hypoxia-inducible factors is correlated with the presence of a fibrotic focus and angiogenesis in pancreatic ductal adenocarcinomas. Histopathology 46 668-676.

Díaz-Sánchez V, Morimoto S, Morales A, Robles-Díaz G \& Cerbón M 1995 Androgen receptor in the rat pancreas: genetic expression and steroid regulation. Pancreas 11 241-245.

Dorsch M, Qiu Y, Soler D, Frank N, Duong T, Goodearl A, O’Neil S, Lora J \& Fraser CC 2005 PKI/EG-VEGF induces monocyte differentiation and activation. Journal of Leukocyte Biology 78 426-434.

Fernández-del Castillo C, Díaz-Sánchez V, Varela-Fascinetto G, Altamirano A, Odor-Morales A, López-Medrano RM \& Díaz-Robles G 1991 Testosterone biotransformation by the isolated perfused canine pancreas. Pancreas $\mathbf{6}$ 104-111.

Ferrara N, LeCouter J, Lin R \& Peale F 2004 EG-VEGF and Bv8: a novel family of tissue restricted angiogenic factors. Biochimica et Biophysica Acta 1654 69-78. 
Fraser HM, Bell J, Wilson H, Taylor PD, Morgan K, Anderson RA \& Duncan WC 2005 Localization and quantification of cyclic changes in the expression of endocrine gland vascular endothelial growth factor in the human corpus luteum. Journal of Clinical Endocrinology and Metabolism 90 427-434.

Ganepola GA, Gritsman AY, Asimakopulos N \& Yiengpruksawan A 1999 Are pancreatic tumors hormone dependent? A case report of unusual, rapidly growing pancreatic tumor during pregnancy, its possible relationship to female sex hormones and review of the literature American Surgeon 65 105-111.

Goi T, Fujioka M, Satoh Y, Tabata S, Koneri K, Nagano H, Hirono Y, Katayama K, Hirose K \& Yamaguchi A 2004 Angiogenesis and tumor proliferation/metastasis of human colorectal cancer cell line SW620 trasfected with endocrine gland-derived-vascular endothelial growth factor, as a new angiogenic factor. Cancer Research 15 1906-1910.

Hidalgo Pascual M, Ferrero Herrero E, Castillo Fé MJ, Guadarrama González FJ, Peláez Torres P \& Botella Ballesteros F 2004 Epidemiology and diagnosis of the pancreatic cancer. Revista Española de Enfermedades Digestivas $\mathbf{9 6}$ 714-722.

Kaser A, Winklmayr M, Lepperdinger G \& Kreil G 2003 The AVIT protein family: secreted cysteine-rich vertebrate proteins with diverse functions. EMBO Reports 4 469-473.

Kisliouk T, Podlovni H \& Meidan R 2005 Unique expression and regulatory mechanisms of EG-VEGF/prokineticin-1 and its receptors in the corpus luteum. Annals of Anatomy 187 529-537.

Konduri S, Schwarz MA, Cafasso D \& Schwarz RE 2007 Androgen receptor blockade in experimental combination therapy of pancreatic cancer. Journal of Surgical Research 142 378-386.

Koong AC, Mehta VK, Le QT, Fisher GA, Terris DJ, Brown JM, Bastidas AJ \& Vierra M 2000 Pancreatic tumors show high levels of hypoxia. International Journal of Radiation Oncology, Biology, Physics 48 919-922.

Koyama Y, Kiyo-oka M, Osakada M, Horiguchi N, Shintani N, Ago Y, Kakuda M, Baba A \& Matsuda T 2006 Expression of prokineticin receptors in mouse cultured astrocytes and involvement in cell proliferation. Brain Research 27 65-69.

LeCouter J \& Ferrara N 2002 EG-VEGF and the concept of tissue-specific angiogenic growth factors. Seminars in Cell and Developmental Biology 13 3-8.

LeCouter J, Kowalski J, Foster J, Hass Phill, Zhang Z, Dillard-Telm L, Frantz G, Rangell L, DeGuzman L, Keller G et al. 2001 Identification of an angiogenic mitogen selective for endocrine gland endothelium. Nature 201 877-884.

LeCouter J, Zlot C, Tejeda M, Peale F \& Ferrara N 2004 Bv8 and endocrine gland-derived vascular endothelial growth factor stimulate hematopoiesis and hematopoietic cell mobilization. PNAS 101 16813-16818.

Lygidakis NJ, Jain S, Sacchi M \& Vrachnos P 2005 Adenocarcinoma of the pancreas: past, present and future. Hepatogastroenterology 52 1281-1292.

Morales A, Cuellar A, Ramirez J, Vilchis F \& Diaz-Sanchez V 1999 Synthesis of steroids in pancreas: evidence of cytochrome P-450scc activity. Pancreas 19 39-44.
Morales A, Vilchis F, Chávez B, Chan C, Robles-Díaz G \& Díaz-Sánchez V 2006 Expression of steroidogenic factors 1 and 2 in normal human pancreas. Journal of Steroid Biochemical Molecular Biology 98 254-258.

Morales A, Vilchis F, Chávez B, Chan C, Robles-Díaz G \& Díaz-Sánchez V $2007 a$ Expression of EG-VEGF in normal human pancreas and adenocarcinoma pancreatic. Journal of Steroid Biochemical Molecular Biology 107 31-40.

Morales-Miranda A, Robles-Díaz G \& Díaz-Sánchez V $2007 b$ Steroid hormones and pancreas: a new paradigm. Revista de Investigación Clínica 59 124-129.

Morimoto S, Fernandez-Mejia C, Romero-Navarro G, Morales-Peza N \& Diaz-Sanchez V 2001 Testosterone effect on insulin content, messenger ribonucleic acid levels, promoter activity and secretion in the rat. Endocrinology 142 1442-1447.

Negi SS, Agarwal A \& Chaudhary A 2006 Flutamide in unresectable pancreatic adenocarcinoma: a randomized, double-blind, placebo-controlled trial. Investigational New Drugs 24 189-194.

Ngan ES, Lee KY, Sit FY, Poon HC, Chan JK, Sham MH, Lui VC \& Tam PK 2007a Prokineticin-1 modulates proliferation and differentiation of enteric neural crest cells. Biochimica et Biophysica Acta 1773 536-545.

Ngan ES, Sit FY, Lee K, Miao X, Yuan Z, Wang W, Nicholls JM, Wong KK, Garcia-Barcelo M, Luis VC et al. 2007b Implications of endocrine glandderived vascular endothelial growth factor/prokineticin-1 signaling in human neuroblastoma progression. Clinical Cancer Research 13 868-875.

Pasquali D, Rossi V, Staibano S, De Rosa G, Chieffi P, Prezioso D, Mirone V, Mascolo M, Tramontano D, Bellastella A et al. 2006 The endocrine-glandderived vascular endothelial growth factor (EG-VEGF)/prokineticin 1 and 2 and receptor expression in human prostate: up-regulation of EG-VEGF/prokineticin 1 with malignancy. Endocrinology 147 4245-4251.

Robles-Díaz G \& Duarte-Rojo A 2001 Pancreas: a sex steroid-dependent tissue. Israel Medical Association Journal 3 364-368.

Soga T, Matsumoto S, Oda T, Saito T, Hiyama H, Takasaki J, Kamohara M, Ohishi T, Matsushime H \& Furuichi K 2002 Molecular cloning and characterization of prokineticin receptors. Biochimica et Biophysica Acta 1579 173-179.

Zhang L, Yang N, Conejo-Garcia JR, Katsaros D, Mohamed-Hadley A, Fracchioli S, Schlienger K, Toll A, Levine B, Rubin SC et al. 2003 Expression of endocrine gland-derived vascular endothelial growth factor in ovarian carcinoma. Clinical Cancer Research 9 264-272.

Received in final form 7 February 2008

Accepted 20 February 2008

Made available online as an Accepted Preprint 20 February 2008 